\title{
aniki
}

Revista Portuguesa da Imagem em Movimento

Portuguese Journal of the Moving Image

\section{A longa duração nos planos dos jogos digitais: aproximações e empréstimos do cinema André Fagundes Pase ${ }^{1}$ Roberto Tietzmann ${ }^{2}$}

\section{Introdução}

A ideia de que um filme é formado a partir de um conjunto de planos montados em sequência, oferecendo ao espectador uma variação de enquadramentos, ângulos de câmera e durações vinculadas às intenções narrativas dos realizadores, é um dos conceitos centrais deste meio e de suas obras. No fim do século XIX, restava aos pioneiros utilizar os recursos de forma direta, enfileirando os segmentos de película enquanto buscavam amadurecer elipses de tempo e espaço, ações paralelas e a estabilização de códigos de representação para facilitar a comunicação com as plateias, algo alcançado através da decupagem e montagem em meados da década de 1920. Assim, um dos eixos principais da história do cinema acompanha a elaboração e complexificação do que, muitas vezes, é chamado de um sintagma fílmico, o sequenciar linear da obra a ser fruída posteriormente pelo espectador ao longo do tempo de exibição.

A partir daquele momento, faz sentido pensar e analisar os tensionamentos e efeitos provocados pelas modificações expressivas da duração dos planos. Os cortes rápidos de Eisenstein, as longas tomadas possibilitadas pelos filmes digitais décadas depois e todas as demais combinações entre ações, situações, narrativa representada e as durações dos planos formaram um ponto-chave na crítica e na análise fílmica e audiovisual desde então.

Ao mesmo tempo, os últimos cinquenta anos têm marcado uma disputa por espaço nas telas domésticas e pessoais, travada entre conteúdos que são descendentes do cinema (ou o re-exibem) e uma ruptura com esta tradição através dos jogos digitais. Diferenças ontológicas entre os meios, marcados pela predominância do registro em câmera no primeiro e na criação de animações interativas dependentes da capacidade de processamento eletrônico no segundo, deram origem a novos repertórios estéticos que continuam a ser atualizados.

\footnotetext{
${ }^{1}$ PUCRS - Pontifícia Universidade Católica do Rio Grande do Sul - Faculdade de Comunicação Social, Programa de Pós-Graduação em Comunicação Social, 90619900, Porto Alegre, Brasil.

${ }^{2}$ Idem.
} 
Ao invés de paredes, as barreiras entre os meios rapidamente revelaram uma porosidade interessante, apresentando toda a sorte de inspiração e empréstimos de parte a parte, como aponta Poole (2000): filmes identificados por críticos como "semelhantes a videogames" por suas cenas de ação; jogos inspirados por cenas, enquadramentos, personagens e situações de filmes que, inclusive, podem ambicionar expandir ou continuar situações narrativas neles apresentadas. Estes empréstimos e apropriações, mais do que diluir a identidade de cada meio, representam um movimento constante na cultura, em que os meios mais recentes fazem uma re-mediação de características dos pregressos, de maneira a definir sua identidade em continuidades e diferenças, um processo comentado por Bolter e Grusin (2000).

Exemplos destes empréstimos entre cinema e jogos são abundantes e incluem transposições de personagens e enredos de um meio para o outro. Títulos como Adventures of Tron ( $A P h$ Technological Consulting, 1982), Raiders of the Lost Ark (Atari, 1982) e Star Wars: The Empire Strikes Back (Parker Brothers, 1982), todos para o console Atari 2600, destacam situações e personagens do cinema e os desenvolvem como jogos. O movimento oposto também ocorre e filmes como Lara Croft: Tomb Raider (Simon West, 2001), Wing Commander - Comando Espacial (Chris Roberts, 1999), Street Fighter - A Batalha Final (Steven E. de Souza, 1994) e o recente Warcraft (Duncan Jones, 2016) são tentativas de replicar êxitos dos jogos no cinema, frequentemente com resultados questionáveis. É possível observar que os primeiros três títulos mencionados estão vinculados a franquias de grande orçamento pertencentes ao gênero de ação e aventura, enquanto os três últimos também estão ligados a franquias de propriedades intelectuais oriundas dos jogos, o que nos faz refletir que o vínculo entre jogos e cinema também é frequentemente pautado por interesses comerciais, algo que viria a ser organizado sob o termo guarda-chuva de transmídia. Ainda assim, comum a todos eles está uma busca de semelhança entre o que é representado na tela do jogo digital e o que é conhecido a partir do filme ou vice-versa, sob pena de uma sensação de autenticidade ser perdida e, assim, frustrar parte dos consumidores.

Cabe aqui recordar que as aproximações entre jogos e cinema também serviram, em outros momentos, para a arqueologia da formação - e consequente discussão sobre o assunto - acerca dos espaços utilizados na diegese proposta na tela. Além da reconstrução proposta por Huhtamo (2013), destaca-se a proposta de Wolf (2001). Ao classificar as representações espaciais na tela, este recorda que não só os jogos eletrônicos permitem algumas vezes a livre exploração sobre um espaço, mas também aspectos técnicos influenciam as possibilidades de construção de uma proposta gráfica. Para permitir que o jogador avance cada fase, o jogo necessita processar os elementos que eventualmente serão distribuídos. Além 
disso, ainda há a necessidade de renderizar e controlar elementos como non-player characters (NPCs) e suas respetivas inteligências artificiais.

Muitas vezes estas produções buscam replicar em um meio situações encontradas no outro. Um adensamento narrativo e estético dos jogos passou pela inclusão de cut-scenes ou cinematics, segmentos em que a possibilidade de agir do jogador é reduzida, ou mesmo suprimida, em prol de apresentar cenas pré-animadas com características de roteiro, decupagem, montagem e interpretação que se aproximam das encontradas em filmes com temática semelhante ao jogo. Nestes segmentos identificamos uma incorporação direta de referências e linguagens, mas dedicamos nossa atenção neste artigo aos momentos de interação propriamente ditos, quando o jogador está engajado com os desafios propostos pelo jogo, por neles identificar os principais motivos de atração e especificidade do meio.

Assim, um ponto em especial separa os meios em diálogo: jogos digitais representam preferencialmente suas ações e situações lúdicas a partir do que pode ser identificado como planos contínuos de longa duração, frequentemente traduzindo o progresso do jogador em um avançar geográfico por espaços, e reduzindo o valor de elipses como elementos significativos da narrativa, se esta estiver presente. Esta é uma escolha que migrou das representações em duas dimensões para as representações tridimensionais dos espaços de jogo, que se mantém ao longo dos avanços em armazenamento e processamento das plataformas e também é encontrada ao longo das mais variadas temáticas de jogos. Do labirinto de Pac-Man (Namco, 1980), permanente mesmo na mudança de fases, à exploração das ruínas de Tomb Raider (Eidos Interactive, 1996), até ao cenário extenso de um mundo de fantasia de The Legend of Zelda: Breath of the Wild (Nintendo, 2017), as experiências de jogo são conduzidas predominantemente em longos planos-sequência.

A partir destas reflexões iniciais, estabelecemos o tema de investigação proposto neste artigo ao questionarmos a razão pela qual os jogos acabaram por eleger uma estética centrada em planos de longa duração como escolha preferencial e de que modo o legado estético e teórico do cinema pode contribuir para o entendimento das escolhas e representação em jogos digitais. Assim, buscaremos situar neste artigo o uso de planos de longa duração em jogos a partir da referência estabelecida em filmes, tendo como base o texto "A Montagem Proibida” de André Bazin.

\section{Meios distintos: afinidades e afastamentos}

Para começarmos a entender os motivos que levaram os jogos digitais a adotar planos longos como uma escolha preferencial é preciso observar diferenças específicas nos alicerces de técnica e tecnologias que separam o cinema dos jogos e vice-versa. 
Observamos que ambos sofrem mudanças ao longo do tempo, conforme Darley (2000), Kent (2001), Napoli (2010) e Palmer (2006), entre outros. No caso do cinema, seus primeiros noventa anos foram impulsionados como mercado global pela estandardização da bitola de $35 \mathrm{~mm}$ como formato principal de captação e distribuição, situando as transformações técnicas e tecnológicas na produção das imagens e banda sonora. Mesmo os filmes épicos de ação e aventura da primeira década do século XXI, ricos em efeitos visuais produzidos digitalmente com técnicas semelhantes às utilizadas em animações e jogos digitais, chegaram às salas de exibição em rolos de filme compatíveis com os projetores veteranos.

Isto reflete um modelo de negócios da indústria cinematográfica, em que o grande investimento na produção do filme recai sobre os seus realizadores, cabendo aos exibidores e à plateia um investimento proporcionalmente menor. Desta maneira, toda a preparação e processamento já estão concluídos quando o filme chega às telas e o aparato de exibição, tanto em espaços domésticos quanto públicos, é comparativamente mais simples. Aparelhos como um reprodutor doméstico de filmes exigem pouco esforço dos equipamentos ou de seus usuários para exibir os conteúdos.

Os jogos digitais oferecem um panorama distinto. Quando um olhar é lançado a partir de um ponto de vista do cinema em direção aos jogos, uma das primeiras perceções é que, na maioria das vezes, suas imagens são criadas a partir de animações que interagem em tempo real com comandos e ações do jogador. De modo distinto do cinema, isso coloca um peso sobre o dispositivo que executa o jogo, seja um console, um smartphone ou um computador pessoal. $\mathrm{O}$ fato de o processamento não vir pronto impulsiona, conforme Kent (2001), uma constante competição e troca de plataformas, que possibilitam avanços na representação, novos comandos e novas ações para alcançar a fruição da experiência lúdico-narrativa, em um engajamento ativo e pessoal incomum no cinema. Ainda que o cinema tenha tido alguns exemplos de tentativas de alcançar o chamado "cinema interativo" exibido coletivamente em salas, a experiência continua sendo semelhante a uma exibição fisicamente passiva, em que os processos de subjetividade e interpretação de cada espectador são as principais ações.

Em jogos, como afirmam Montfort e Bogost (2009), o aumento da capacidade técnica determina a complexidade das representações visuais, enquanto as mudanças nos dispositivos de entrada delimitam a quantidade de ações possíveis para o jogador e, portanto, sua capacidade de informar suas intenções. No Atari 2600, por exemplo, o icônico joystick permite movimentos em oito direções com apenas um botão para ação, um repertório de gestos que limitava a complexidade da comunicação do jogador para o jogo 
a ações simples, desprovidas de nuances de emoção ou intenção que outras formas de entrada desenvolveram nas décadas seguintes.

As ruturas de paradigmas técnico-tecnológicos em ambos os campos, usando um termo de Kuhn (2013), potencializaram as possibilidades de manipulação do audiovisual a partir da digitalização dos processos vinculados às imagens em movimento $\mathrm{e}$ uma complexidade na criação de imagens e situações de jogo que as tornam quase indistintas visualmente de imagens produzidas por câmeras, em uma contaminação de estéticas contínua. Isto nos faz retornar à nossa pergunta inicial: uma vez que os jogos transformam constantemente seus mecanismos de tecnologia, porque continuam a usar planos longos para representar as partidas?

\section{Pontos de partida cinematográficos: vistas, tableaux e planos}

Para compreender os vínculos que aproximam e separam a longa duração de planos nos dois meios, é preciso observar marcas estabelecidas no começo do cinema, inspiradoras de formas de visualidade nos jogos digitais décadas depois.

O cinema na década de 1890 contava com dois modos de representação distintos dos contemporâneos, ainda que amplamente difundidos: a vista (a partir do francês vue) e o tableau, conforme Siety (2001). Ambas largamente independem da montagem como um recurso capaz de sugerir significados, uma vez que ideias como a continuidade de movimento entre os trechos, a orientação espacial do espectador, a causalidade narrativa e a unidade temporal eram incipientes. Sustentamos que ambos deixaram legados na representação contemporânea dos jogos digitais e permanecem relevantes mesmo após sucessivos avanços tecnológicos.

A vista se caracteriza por apresentar cenas sem corte de diversos lugares e situações, com duração proporcional à capacidade das câmeras. Segundo Abel (2005), as vistas eram parentes diretos do cartão postal fotográfico, seu ancestral imediato. Ambos faziam circular paisagens do mundo e de seus costumes e guardavam uma retórica de transparência do dispositivo técnico de captura e exibição, fazendo da imagem uma "janela" verossímil para outros espaços. Grande parte das imagens não representava um elemento de uma narrativa, mas apenas operava uma mostração, como colocam Jost e Gaudreault (2010), estando sua interpretação calcada no contexto cultural do espectador. O que as imagens mostravam essencialmente respeitava as noções de perspetiva, movimento, espaço e tempo comentadas por Helfand:

Desde o século XV até o início do século XX, nossa compreensão do espaço-tempo era unida por uma crença inabalável nos quatro pilares da realidade física, enquadrados pelo que é rotineiramente considerado como um tipo de paradigma Newtoniano: espaço, tempo, energia e massa. Como o espaço euclidiano, que define o 
pensamento direcional em vetores (para cima, para baixo, direita e esquerda), o conceito ocidental de espaço era absoluto: ilimitado e infinito, plano e inerte, conhecível e fixo. $(2001,35)$

As vistas representavam a maioria da produção cinematográfica dos primeiros anos do meio e atraíam o público por conta da novidade do aparato e de sua capacidade de registrar o efêmero. No final do século XIX, seu poder de atração começou a se mostrar saturado, perdendo espaço para formas mais elaboradas de representação.

As vistas, em um primeiro momento, poderiam ser entendidas como um representante do que é especificamente cinematográfico, portanto de difícil transferência para outros meios. Se observarmos que os jogos são tecnicamente mais próximos de filmes de animação do que os live action, é possível argumentar que uma vista seria algo inviável de ser alcançado: ela dependeria da capacidade de uma câmera registrar o efêmero em um espaço virtual. Contudo, espaços tridimensionais de jogo são representados a partir de câmeras virtuais com características semelhantes às materiais, como profundidade de campo e distância focal, além do design das fases do jogo (conhecido como level design), quando este representa progresso em uma narrativa. Assim, é possível entender ser viável a elaboração de vistas dentro de espaços de jogo digital, ainda que tais realizações normalmente estejam desvinculadas dos objetivos principais das partidas.

Quando as vistas são incorporadas às partidas, normalmente são usadas de três formas: como uma visão panorâmica no espaço de jogo, o aviso de uma progressão em uma fase ou etapa, ou como uma possibilidade de contemplação em meio às atividades principais.

O primeiro caso é mais próximo das vistas como eram entendidas no cinema, oferecendo um panorama do futuro campo de jogo. Alguns exemplos incluem o sobrevôo do campo do labirinto ao início de cada fase nos jogos da série Super Monkey Ball (Amusement Vision, 2001) ou o movimento de câmera panorâmico nas aberturas de fases dos dois jogos de Super Mario Galaxy (Nintendo, 2007 e 2009).

No segundo caso, podemos citar jogos de ação como Altered Beast (SEGA, 1987), Double Dragon (Technōs Japan, 1987) e Teenage Mutant Ninja Turtles (Konami,1989), pois suas tramas - salvar a deusa grega Athena raptada pelo demônio Neff, resgatar a jovem raptada pela gangue rival e impedir que o vilão Shredder ataque a Terra, respetivamente - ocorrem através de fases que progridem horizontalmente, ao passo que o jogador elimina todos os desafios de um determinado segmento. Caso o jogador não movimente seu personagem para prosseguir adiante, um indicador surge na tela sinalizando o avanço a ser feito. 
Por fim, jogos que permitam a movimentação livre do jogador pelo espaço, como a série Grand Theft Auto (Rockstar Games, 1997), frequentemente incluem pontos de observação e contemplação, instâncias do terceiro caso. Isto também está presente no jogo Endless Ocean (Arika, 2007), em que o jogador pode escolher partir imediatamente para uma missão de mergulho ou repousar e olhar a paisagem do convés do navio. Em todos os casos, ressaltamos, parte das características formais das vistas foi incorporada, mas não sua característica de produto comercial presente nos primeiros anos do cinema.

O primeiro passo em direção a uma enunciação mais complexa no cinema foi o tableau, uma solução intermediária entre o aproveitamento das capacidades de registro mecânico das câmeras e o legado do teatro e das artes plásticas, além de emprestar o nome das brincadeiras de Tableaux Vivants, citadas por Peucker (2007) e Jacobs (2011), em que se buscava reproduzir, com pessoas, imagens de obras de arte conhecidas em uma cena estática, imitando seus figurinos, cenários, posições e gestos. Uma significativa parte da estética de jogos digitais também se relaciona com estes tableaux.

Os tableaux eram descendentes de uma cisão entre o teatro do período elisabetano e seus sucessores, em que o uso de recursos tecnológicos para dar visualidade à encenação das narrativas foi estendido do século XVIII em diante, com a incorporação de palcos móveis, alçapões e outras soluções mecânicas, que viriam a colaborar com óperas e outros espetáculos conforme indicam Bianconi, Pestelli e Singleton (2002). Miller (2006) e Ruffles (2004) afirmam que o teatro do século XIX, nas décadas anteriores ao cinema, usava com regularidade raios, arco-íris, enchentes, fogo e fumaça. Segundo os autores, eram frequentes os espetáculos que incorporavam aparições e espíritos, realizados através de projeções variadas com dispositivos derivados de lanternas mágicas.

O tableau cinematográfico se caracteriza pela frontalidade no posicionamento da câmera, pelo aproveitamento limitado da perspetiva e por privilegiar o desenvolvimento da ação dramática da cena do início ao final sem cortes, frequentemente recorrendo a uma sofisticada coreografia e esmero na direção de arte. Conforme Bazin,

Os enquadramentos em um filme de 1910 buscam, com todas as intenções e objetivos, ser um substituto para a ausente quarta parede do palco teatral, ou, pelo menos em planos externos, no melhor ponto para ver a ação, onde no segundo caso a ambientação, a iluminação e os ângulos de câmera proporcionam uma leitura completamente distinta. Entre eles, o diretor e o operador de câmera converteram a tela em um tabuleiro de damas, planejado nos mínimos detalhes. $(1991,51)$

Uma vista ou um tableau não eram planos, como se convencionou chamar posteriormente o resultado do processo de decupagem e futura matéria-prima para o trabalho do montador. 
Tableaux eram, ao mesmo tempo, mais do que planos (porque ambicionavam mostrar situações mais extensas) e menos do que planos (uma vez que eram insuficientes para representar narrativas mais complexas e estruturadas).

A utilização de uma perspetiva frontal para o enquadramento das ações e a construção dos espaços é algo bastante conhecido em jogos, em especial nos títulos dos primeiros 20 anos no entretenimento digital. Fruto de restrições de processamento e memória dos sistemas, frequentemente as ações ocorriam em uma única tela com pequenas variações ou em sequências de telas subsequentes, nas quais a apresentação das ações possíveis, a relação dos avatares do jogador com os demais personagens e o próprio desenrolar dos desafios poderiam ser alinhados com o comentário a respeito do cinema dos primeiros anos: era uma composição controlada e planejada para oferecer diversão ao espectador.

Exemplos desta inspiração vinda do primeiro cinema estão presentes em praticamente todos os gêneros de jogos digitais, desde jogos de luta como Karate Champ (Technōs Japan, 1984) e Yie Ar Kung Fu (Konami, 1985), plataforma como Donkey Kong (Nintendo, 1981) ou Bomb Jack (Tehkan, 1984), tiro com Space Invaders (Taito, 1978), Galaxian (Namco, 1979) e Galaga (Namco, 1981) entre outros tantos. No labirinto de Berzerk (Stern, 1980), lançado para arcades e consoles domésticos ${ }^{3}$, a sequência do jogo utilizava este expediente, resultando em uma experiência que exemplifica esta ligação do tableau como um recurso técnico diante das possibilidades tecnológicas em constante evolução.

Após destruir robôs em uma tela, o jogador pode escolher um caminho a seguir entre as lacunas presentes nos cantos da tela. Ao realizar esta ação, uma nova tela é apresentada em corte, substituindo totalmente a anterior sem transições. Cada fase é um "tabuleiro" novo proposto na tela, com outras paredes e possibilidades de escape. Caso o jogador morra, um novo labirinto surge na vida seguinte.

A diagramação das telas, no entanto, guardava uma diferença fundamental da inspiração vinda do cinema: havia emprestado a organização de espaço a partir dos tableaux, mas até a década de 1990 era inviável representar personagens e avatares de tamanhos grandes, o que aproximava muitos enquadramentos presentes em jogos do que é identificado em análise fílmica como um grande plano geral. Samurai Shodown (SNK, 1993), foi uma das primeiras produções a alterar isto com o uso de um zoom para mostrar os jogadores durante séries de lutas. Quando os personagens estão próximos, a imagem aproxima o ponto de vista, recuando quando cada um dos lutadores for até os extremos da tela. Cabe recordar que

\footnotetext{
${ }^{3}$ O jogo teve versões para os consoles Vectrex, Atari 2600 e Atari 5200, lançadas após o arcade.
} 
este recurso não está disponível nas versões para Super Nintendo e Mega Drive/Genesis, precisamente pela limitação dos consoles de 16-bit.

Como um ponto ontológico específico dos jogos, o foco de atenção na tela é dado primeiro por uma perceção de comando e reação. Ou seja, assim que o jogador mover o controle, percebe qual é o seu avatar no espaço disponível da tela. Isto define o registro de atenção, uma característica fundamentalmente diferente do cinema.

Uma vez que foram superadas as oposições entre vista $e$ tableau, os filmes foram complexificados pelas estratégias de montagem baseadas na seleção, organização, afinamento de cortes e mixagem dos planos, como situa Pinel (2001), predominantemente vinculados à construção de cenas reguladas por uma narrativa. Como resultado, cada plano se tornou progressivamente menos independente dos demais e mais integrado a um discurso fílmico em que produz sentido.

\section{Jogos digitais, não digitais e seus legados}

A longa duração presente nos planos dos jogos digitais não é um empréstimo apenas do primeiro cinema, mas também de convenções estabelecidas desde os jogos não-digitais que acompanham a Humanidade há milênios.

Estas definições foram propostas inicialmente por Huizinga (2012), ao observar a importância dos jogos no cotidiano, aperfeiçoadas para os jogos eletrônicos a partir de Crawford (1982) e refinadas por Salen e Zimmerman $(2003,80)$, com a proposição de um conceito de jogo como "um sistema cujos jogadores estão engajados em um conflito artificial, definido por regras, e que produz um resultado quantificável”4.

Essencialmente, todos os jogos compartilham quatro características definidoras: pelo menos um objetivo, um conjunto de regras que podem ser aprendidas e um sistema de feedback, e dependem da participação voluntária dos participantes. Este conceito irmana as mais recentes versões dos consoles com exemplos atemporais como o xadrez, uma vez que estabelece a necessidade por parte do jogador de aprender ou atualizar o conhecimento a cada novo jogo com que toma contato, de maneira que possa desenvolver sua agência e habilidade, o que tem relação com a duração dos planos nos jogos digitais.

Segundo Koster (2005), o sentimento de gratificação em um jogo depende diretamente de enfrentar o desafio de conhecer o

\footnotetext{
${ }^{4}$ Tradução livre dos autores para o original "A game is a system in which players engage in an artificial conflict, defined by rules, that results in a quantifiable outcome."
} 
sistema de regras e conseguir estar um passo adiante delas, de modo que, ao alcançar a previsibilidade completa, também a diversão acabaria. Partidas solitárias contra a máquina podem chegar a este patamar mais rapidamente do que rodadas contra oponentes humanos, dada sua capacidade de improviso e a imprevisibilidade quando em competição.

Os jogos digitais, sobretudo em virtude das suas possibilidades de representação, são visualmente criativos, envolventes em seu apelo aos sentidos e amplamente restritivos. Por exemplo, um jogo do gênero luta como Street Fighter II: The World Warrior (Capcom, 1991) dificilmente pode ser usado em um "modo pacifista", em que os jogadores usariam os botões com golpes designados para fazer afagos no outro avatar em tela. Uma vez que esta opção não foi programada, o gráfico de um dos lutadores irá empurrar o outro adiante, até o limite da tela, se assim prosseguir, até o ponto em que ambos estarão tocando um no outro sem provocar dano nem pontuação, distanciando-se dos objetivos do jogo: liquidar os oponentes até à vitória final no torneio. Ao término do tempo de 99 segundos, a rodada será suspensa e a mensagem de luta empatada surgirá na tela. Este exemplo permite argumentar que quem escolhe um jogo possui uma noção básica do que esperar e, portanto, aceita as regras definidas ou rapidamente conhecidas. O comentário é irônico, mas o fato é que as regras de cada jogo colocam tantas limitações quanto possibilidades a quem se engaja com o esforço voluntário de levar uma partida adiante.

Podemos argumentar que o espaço de jogo de Street Fighter II, ao apresentar um enquadramento suficiente para os dois lutadores em um espaço praticamente bidimensional, é um descendente direto dos tableaux cinematográficos, mas a constância dos cenários está vinculada também à tradição dos jogos de tabuleiro em que os jogadores tinham a visão completa do espaço de jogo. Aprender a lidar com as regras de competição dentro deste espaço limitado significava estar mais próximo da vitória.

Wolf (2001) propõe uma classificação dos espaços de jogo em 11 distribuições visuais. Elas vão desde os jogos baseados apenas em texto, como Zork (1980), até a representação de mundos completos, como Myst (1993). A lista compreende jogos sem projeção espacial, baseados em texto; contidos em uma tela; contidos em uma tela mas transpassada; desenvolvidos através da rolagem através de um eixo; desenvolvidos através da rolagem através de dois eixos; composto por espaços adjacentes exibidos um de cada vez; composto por camadas com movimentos independentes; formado pelo conjunto de espaços com movimento por um eixo $z$ dentro e fora da tela; composto por múltiplos espaços não-adjacentes e exibidos simultaneamente; ambientes interativos tridimensionais; e mimese ou representação de espaços. 
Embora incontáveis jogos digitais criados durante a década de 70 e início dos 80 do século XX tenham resolvido suas situações de jogo, mostrando uma espécie de tabuleiro fixo na tela, em que todas as opções de jogo já estavam desenhadas, a evolução das plataformas abriu outras possibilidades expressivas.

Já na primeira metade da década de 80, o tabuleiro eletrônico expandiu seu território para além do que era possível representar de uma só vez a cada tela. Telas que rolavam o cenário quando o personagem chegava próximo de uma borda e pistas de corrida "infinitas" rumando sempre em frente, indicam o empréstimo de alguns conceitos de enquadramentos vindos do cinema e de focalização de ação e narrativa. Eles sugeriam que, embora as ações estivessem circunscritas ao espaço imediato onde o jogador estava operando, havia algum espaço maior que poderia ser conhecido e explorado. E é neste momento que começa a se consolidar a mescla entre as convenções do cinema, que indica a riqueza da imagem como uma meta a ser alcançada a cada aumento das capacidades gráficas, e a tradição vinda dos jogos de permitir ao jogador o conhecimento do tabuleiro através da manutenção de uma regularidade dos espaços. Ao negociar a expansão do primeiro com a restrição do segundo foi elaborada e adotada coletivamente a ideia de longa duração, em que uma fase se desenrolará ao longo do tempo e do espaço e estes estariam alinhados, evitando cortes de cena que poderiam confundir a agência do jogador.

Nesse sentido, jogos e filmes também se afastam. Em um filme normalmente o andamento por espaços geográficos é determinado pela necessidade da narrativa, uma vez que o espectador não tem autonomia para percorrer o cenário se esta área não é utilizada como espaço para nenhuma ação de seus personagens, sejam protagonistas ou coadjuvantes. Em O Cavaleiro das Trevas Renasce (Christopher Nolan, 2012), por exemplo, não é possível explorar a cidade de Gotham City para além das imagens mostradas na tela, por mais que os planos reforcem a sugestão de existência de diversos espaços para visitação além daqueles percorridos por Batman. Já em Batman: Arkham Knight (Rocksteady, 2015), para utilizar o mesmo universo fictício como exemplo, é possível explorar a cidade com maior liberdade, mesmo que uma determinada missão necessite ir do ponto A até o B no mapa. No universo do jogo, muitas vezes é possível regressar para tais espaços mesmo que isso afaste o jogador das mecânicas preferenciais da partida, o que pode revisitar tradições das vistas cinematográficas como discutido anteriormente.

De qualquer maneira, jogos digitais utilizam aspectos espaciais e geográficos para pautar o andamento de suas ações e desafios. E é justamente aí que a problematização deste artigo permite detetar e compreender um movimento: a maioria dos jogos digitais com representações tridimensionais realiza isto em longos planossequência de ações e avanços do jogador, por fases elaboradas para 
regular desafios de forma prazerosa ao ato de agir na resolução de um conflito, o que indica um caminho adicional para a compreensão entre jogos e cinema.

\section{Relendo a "Montagem Proibida" como uma chave de compreensão da longa duração nos jogos digitais}

No texto "A Montagem Proibida", Bazin defende que a presença de ação e reação dentro do mesmo plano é fundamental para aumentar a verossimilhança de uma imagem cinematográfica, ou, em suas palavras,

a tela reproduz o fluxo e o refluxo de nossa imaginação, que se nutre da realizada à qual ela projeta se substituir; a fábula nasce da experiência que ela transcende. Mas, reciprocamente, é preciso que o imaginário tenha na tela a densidade espacial do real. A montagem só pode ser usada aí dentro de limites precisos, sob pena de atentar contra a própria ontologia da fábula cinematográfica. $(1991,60)$

Entendemos que o texto, escrito originalmente na década de 50 do século XX, tem muito a dizer, mesmo para o panorama dos jogos digitais contemporâneos. Em primeiro lugar, Bazin coloca o cinema como um articulador entre a imaginação e a experiência do mundo, um tema que podemos argumentar ser verdadeiro também para os jogos. Nem todos os filmes, assim como nem todos os jogos, refletem o mundo existente fora da tela. Mas, ao buscar a adesão de espectadores e jogadores, invariavelmente será buscado algum apelo emocional. Desta maneira, mesmo o jogo situado em um ambiente totalmente de fantasia terá a possibilidade de uma ligação com os sentimentos de seus jogadores, de modo a motivá-los a continuar na partida. Se o jogo permanecesse demasiado próximo do mundo existente, ele perderia, como Bazin prevê, sua própria ontologia e se tornaria então um simulador.

O segundo ponto da citação destacada tem sua chave de interpretação a partir do que Bazin coloca como a densidade espacial do real, um conceito simples de entender, mas fugaz em sua definição. Essencialmente significa uma restrição à incorporação de uma imaginação ativa sobre a representação do mundo na tela. Nas circunstâncias em que a imaginação espacial corre solta nas telas dos cinemas, o espectador encontra sequências de sonho e sequências de montagem com um propósito mais sensorial do que de representação de um espaço coerente. Aqui, Bazin defende uma empatia que nasce da observação pelo espectador dos personagens agindo sobre seu espaço e experienciando as reações materiais dele, e isto é um dos pontos principais da ligação da "montagem proibida" com os planos de longa duração nos jogos digitais.

Uma vez que os jogos digitais estão mais próximos do cinema de animação, a consistência desta densidade espacial do real precisa ser 
reforçada como um contrato de leitura entre autores e jogadores do jogo. A partir de um espaço consistente é possível constituir um jogo com regras estáveis, o que alinha a trajetória dos jogos digitais com a própria história do cinema, que amadureceu em suas primeiras décadas até encontrar um código de representação dos espaços estável o suficiente que operasse através dos cortes e das convenções de montagem. Além disto, uma vez que os jogadores através de seus avatares agem sobre o espaço digital, também é esperado que a consistência e a permanência dos objetos virtuais dispostos sobre o cenário seja mantida, o que reforça ainda mais as restrições a presença de cortes de imagem.

Como terceiro ponto, podemos afirmar que o texto de Bazin parte da representação de um elemento de fantasia dentro de um mundo verossímil: o balão vermelho que acompanha o menino, tal como um animal de estimação o faria em $O$ Balão Vermelho (Albert Lamorisse, 1956). Ainda que as regras da física filtradas pelas convenções da narrativa cinematográfica pareçam se aplicar às ruas da cidade representada no filme, bem como ao menino, a autonomia dos movimentos do balão sublinha a importância de mostrar ações e reações dentro dos mesmos planos como uma maneira de sustentar a verossimilhança do fantástico. Este conceito dialoga com as escolhas presentes na representação de jogos digitais, em que o engajamento do jogador se dá através da identificação e do feedback de sua agência sobre os espaços no seu entorno, o que acontece em planos longos que reúnam ações e reações.

Cabe ressaltar que, nos jogos eletrônicos, o movimento de corte de imagem de um plano para o outro pode impactar não apenas em uma passagem de tempo ou mesmo uma mudança de cenário, mas uma mudança no gameplay, nas ações e possibilidades ofertadas pelo jogo que determinam os modos de agir no cenário proposto. Para Spector $(2004,77)$, isto é "o conjunto das experiências vividas a cada minuto que completam e/ou satisfazem a experiência do jogo. Consiste nos sistemas de jogo, recursos, escolhas dos jogadores e interações entre esses elementos."

Regressando às primeiras máquinas de arcades e ao Atari 2600, observamos como apresentar um jogo em um único plano delimitado (tableau) ou uma progressão no cenário (vista) estava também limitado ao potencial da máquina. Jungle Hunt (Taito, 1982) apresenta uma das primeiras distensões destes conceitos, ilustrado nas imagens 1-3. 

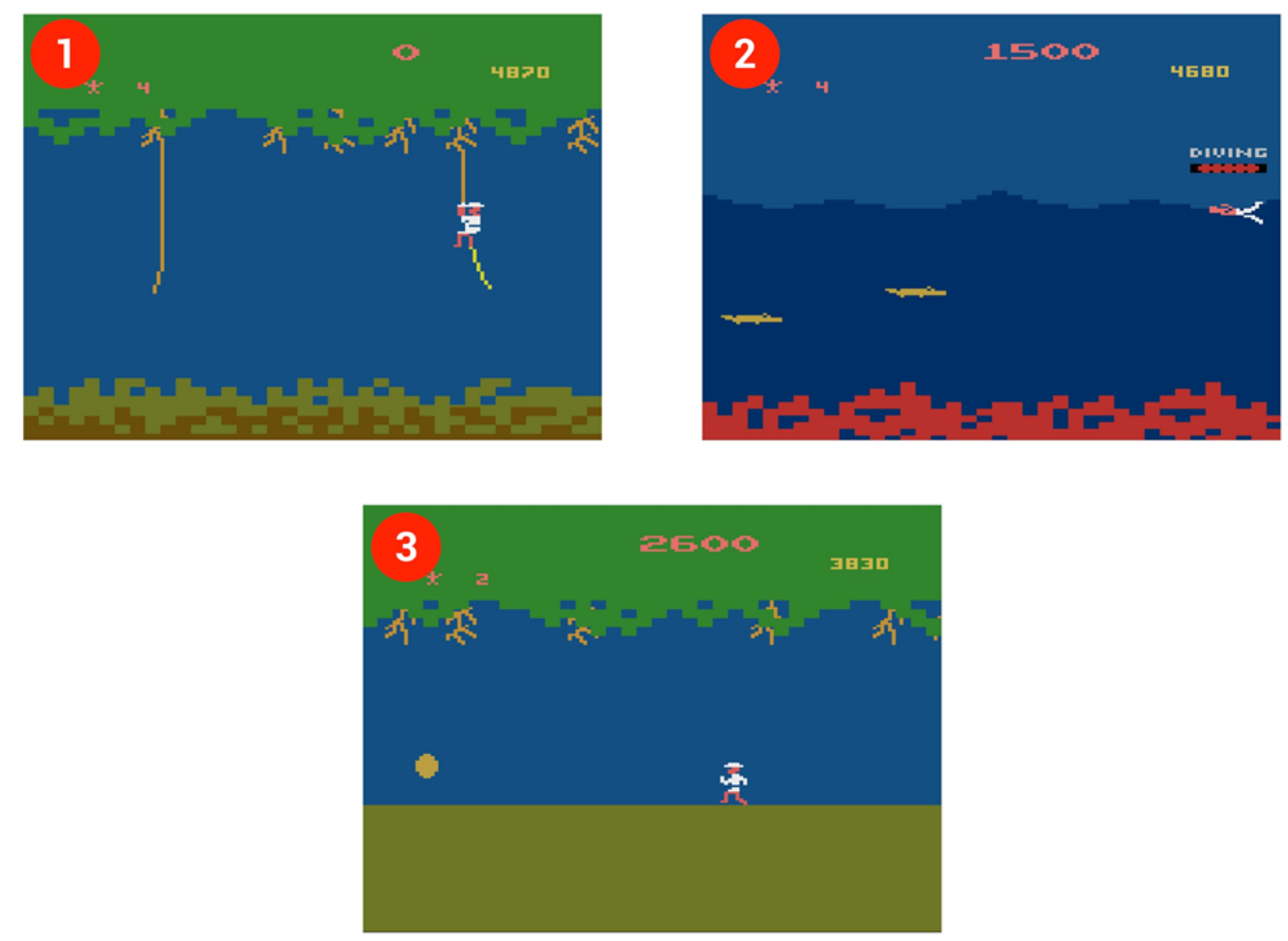

Imagens 1-3: Jogo Jungle Hunt (Atari, 1982) | (c) Atari

A imagem é uma composição das três fases distintas de Jungle Hunt, cujo objetivo era percorrer uma selva e resgatar uma mulher raptada por selvagens. Na primeira (identificada com um $\mathrm{n}^{0} 1$ no canto superior esquerdo), era necessário pular de cipó para cipó, progredindo para a esquerda. A tela ao lado $\left(\mathrm{n}^{\circ} 2\right)$ representa o estágio do rio, cujo objetivo é nadar entre jacarés, com a possibilidade de matar os animais. Por fim, o aventureiro regressava à terra $\left(n^{\circ} 3\right)$ e deveria pular ou ficar agachado para desviar de pedras rolantes e selvagens.

Este jogo mostra como três tableaux são estendidos para formar vistas distintas e concatenadas. A expansão das possibilidades tecnológicas não apenas alterava os limites da ação, mas permitia sequências e progressões de maneiras distintas que formam, em conjunto, uma grande narrativa. Neste momento, assim como nas primeiras edições cinematográficas e ao utilizar suas convenções, o jogo eletrônico dialoga com planos e técnicas para esboçar suas primeiras formas de expressão distintas.

Ao conectar Bazin com os jogos eletrônicos e suas possibilidades contemporâneas, observamos como os conceitos de vista e tableau são utilizados para reforçar o que fora postulado pelo autor, porém utilizando o processamento dos consoles para gerar um plano-sequência em tempo real conforme a duração necessária. Os limites do filme e da montagem, quando há uma necessidade de complementar o real, são recombinados quando um cenário é projetado e utilizado, seja para que eventos cinemáticos sejam 
seguidos por momentos de ação do jogador ou planos longos com ampla variedade de perspetivas.

O primeiro limite decorre da transição das cut-scenes para espaços de gameplay de fato. As limitações das plataformas do passado obrigavam os realizadores a utilizar textos, telas com desenhos e, posteriormente, sequências de animação que eram interrompidas no momento da ação, como se precedessem a observação do tableau do jogo. A utilização de gráficos vetoriais nos jogos com a posterior qualidade suficiente para utilização da mesma ferramenta de programação para montar as cenas permitiu combinar animação e gameplay sem uma "quebra" no fluxo da experiência.

Algumas produções permitem observar esta transformação. Em Another World (Delphine Software, 1991), as animações utilizam o mesmo estilo do gameplay vetorizado. Anos depois, The Lord of the Rings: The Return of the King (EA Redwood Shores, 2003) inicia com segmento retirado do filme homônimo cujos frames finais foram produzidos com a engine do jogo e há uma transição rápida e quase impercetível para a ação. Por fim, Quantum Break (Remedy Entertainment, 2016) recombina constantemente imagens renderizadas com segmentos filmados de maneira digital, de forma que o jogador frua uma experiência sem distinção de natureza.

O outro limite é expandido com a transformação das fases. Jogos de ação e aventura, sobretudo, utilizavam progressão através da passagem por planos-sequência. Em jogos de plataforma, cada plano carregava não apenas um cenário novo, mas também novos desafios. A progressão de Super Mario Bros. 1 (Nintendo, 1985) exemplifica isso, ao passo que a rolagem da tela seguia conforme o movimento do jogador o leva adiante na narrativa lúdica. Em Prince of Persia: The Sands of Time (Ubisoft Montreal, 2003), o mesmo recurso do labirinto citado anteriormente em Super Monkey Ball surge como forma de mostrar ao jogador qual o seu objetivo em um cenário; porém, com o uso da variação da banda sonora, conforme são enfrentados os inimigos. Isto ocorre de maneira fluida, sem que o jogador note uma quebra na mudança dos estados do jogo.

Por fim, a série Uncharted exemplifica as possibilidades contemporâneas de conectar segmentos de maneira fluida. Se o jogo de videogame parte de uma premissa ficcional, pois não é possível jogar com a realidade, há uma distensão longa do plano único para colocar o jogador diante de uma situação em que ele precisa agir, porém sem espaços para refletir.

Em jogos de aventura, como The Legend of Zelda: The Wind Waker (Nintendo, 2002), isto ocorre com a liberdade para explorar o mundo ao seu redor. Porém, em Uncharted 2: Among Thieves (Naughty Dog, 2009), o jogador deve controlar o protagonista Nathan Drake enquanto ele percorre um trem em movimento. A 
sequência tem a duração de 15 minutos $^{5}$; porém, é formada por longos segmentos sem cortes aparentes na imagem. Como isto é realizado enfrentando bandidos e até mesmo um helicóptero, ao passo que o trem segue em movimento, a sensação de um plano único é alcançada.

O recurso é resgatado em Uncharted 4: A Thief's End (Naughty Dog, 2016). A busca por uma cidade com os tesouros de diversos piratas leva o protagonista Nathan Drake para diversos locais, inclusive Madagáscar. Após um combate em uma região urbana, ele deve escapar da perseguição de inimigos e resgatar seu irmão, saindo do alto de uma colina até uma estrada localizada no nível do mar (primeiro gameplay, controle de veículo). Chegando lá, acaba por jogar uma corda em um guindaste na caçamba de um caminhão e precisa desviar de obstáculos e atirar em inimigos, enquanto é arrastado (segundo gameplay). Após utilizar a corda para deixar o solo, assume a condução de um jipe e precisa dirigir enquanto combate (terceiro gameplay). A sequência tem cerca de 10 minutos $^{6}$ e conta com apenas dois momentos de pausa para animações, criando uma sensação intensa de movimento ao repetir o expediente do jogo anteriormente mencionado, mas em um cenário com mais elementos em movimento - resultado da mudança do PlayStation 3 para o 4 e seu avanço técnico.

Estes exemplos, sobretudo os últimos, ilustram como consoles atuais permitem criar longos planos com fluxo intenso de ação. $\mathrm{O}$ aventureiro de Jungle Hunt não conta mais com gameplays distintos em virtude de limites tecnológicos, mas em Uncharted a fronteira é formada pela possibilidade de estender ao máximo a atenção do jogador em um estado de tensão. Esta emoção, fruto da combinação da perseguição com o combate e o revelar de novas paisagens, amplificam no jogador a sensação de imersão almejada pelo cinema e pelos jogos, porém aqui com o controle na mão do público - ou, pelo menos, conforme a ilusão projetada pela equipe de design.

Portanto, podemos compreender como ao longo do tempo as vistas, os tableaux e planos foram alterados. Este movimento ocorreu sobretudo após a Quinta Geração de consoles domésticos (formada por 3DO, Jaguar, Nintendo 64, PlayStation e Saturn, entre outros), cujas propriedades técnicas permitiram uma expansão dos jogos projetados em 3D com maior liberdade de câmera.

O principal impacto disto foi observado na possibilidade de observar um ambiente de maneira livre, transformando um tableaux em um grande plano determinado pelo movimento do público. Em jogos como Super Mario 64 (1996), é necessário percorrer castelos e outros espaços, porém em uma ambientação que envolve a profundidade (eixo Z). Esta expansão, auxiliada por técnicas de

\footnotetext{
${ }^{5} \mathrm{O}$ segmento pode ser visualizado no endereço https://youtu.be/b1jJx_RkU9Y.

${ }^{6} \mathrm{O}$ trecho comentado pode ser visualizado em https://youtu.be/GKQcMAhOvPc.
} 
criação de céus e outras formas de limite, ilude o jogador a esquecer que seu espaço de ação é um espaço delimitado em um cenário finito. A diluição desta fronteira também remonta a uma maior possibilidade de processamento, algo observado anteriormente nos simuladores dos computadores pessoais. Em Flight Simulator 2.0 (1984), o piloto poderia voar por todo o território dos Estados Unidos, mesmo que o pouso fosse realizado apenas em alguns aeroportos pré-programados. A possibilidade de movimento da série Uncharted, mencionada anteriormente, ou a exploração do vasto cenário do Caribe em Assassin's Creed IV: Black Flag (2013), entre tantos outros, decorre desta expansão.

O tableaux é expandido, porém seu legado não desaparece. Mesmo quando gerado proceduralmente, como afirma Bogost (2007), ainda decorre de um espaço previamente elaborado. Os planos são alongados em sua duração, em uma fusão entre espaços que amplia possibilidades, dentro dos limites técnicos e, consequentemente, narrativos e lúdicos, ao manter ações e reações sem cortes.

\section{Considerações Finais}

O tema abordado neste artigo é complexo por definição e apresenta um desafio para as comparações e análises propostas: afinal de contas, os meios do cinema e audiovisual e dos jogos digitais guardam semelhanças entre si, mas também significativas diferenças. Uma metodologia de análise fúlmica não pode ser usada diretamente para analisar um jogo, bem como suas correspondentes na área dos Game Studies tampouco dão conta de analisar um filme. Assim, ao longo deste percurso, o que nos resta?

Essencialmente, uma aproximação de análise que nos permitiu traçar alguns pontos de genealogia do uso de planos de longa duração nos jogos. O legado dos tableaux sugeriu uma organização de espaço que tem profundidade, mas que faz com que os personagens transitem muito mais nos eixos horizontais e verticais da tela. Esta fórmula foi e continua a ser amplamente utilizada na criação de telas e interfaces de jogos. A contribuição dos jogos de tabuleiro não pode ser subestimada, uma vez que eles acompanham a Humanidade há milênios, oferecendo um espaço de pedagogia, fantasia e interação social que ajudou a definir as expectativas do que um jogo é capaz de oferecer a quem dele participa. Além disso, jogos de tabuleiro trouxeram um repertório de maneiras de como visualizar o campo de jogo que acabou por mesclar-se com o legado dos tableaux cinematográficos.

O legado de cada uma destas contribuições é frequentemente apresentado mesclado à outra, a ponto de ser difícil identificar os limites entre elas. Por exemplo, se observarmos a tela de uma partida do jogo Pac-Man (Namco, 1980) é possível observar uma clara 
descendência vinda dos jogos de tabuleiro, ainda que a versão digital reponha todas as peças nas posições originais a cada nova fase. Em Pac-Man vemos avatares caricaturais, seres fantasiosos que nunca realmente foram elaborados para serem levados a sério. No entanto, assim que a representação destes avatares de jogo passa a se tornar um pouco mais verossímil, como no caso de jogos que tenham avatares que se assemelham a humanos, se faz presente o legado dos tableaux na construção dos espaços. Comum a ambos está a ideia de que o jogador vai dedicar bastante tempo às ações possíveis em cada tela e que é a permanência dos elementos ali ao longo das partidas que servirá de orientação e aprendizado de como jogar, resultando em ações e reações que acontecem ao longo de planos de longa duração, pontuado por vinhetas de começo e final de partida. A expansão do poder de processamento de consoles resulta, por consequência, na possibilidade de fundir diferentes tableaux de grandes dimensões para formar vistas prolongadas.

A entrada das representações gráficas tridimensionais nos jogos digitais por um lado complexificou estas representações dois pontos: não era mais possível simplesmente dizer que os tableaux organizavam a imagem e as relações dentro dela, especialmente em jogos que dessem ao jogador bastante liberdade para percorrer de seus cenários. Nestes casos, recorremos a Bazin, pois o autor argumenta que, mesmo no cinema, separar ações e reações em diferentes planos pode trazer uma sensação de artificialidade à imagem, sendo recomendável mantê-las dentro do mesmo quadro quando possível.

Nos jogos este é um pensamento constante, uma vez que a adesão do jogador ao desafio proposto está diretamente ligada à sua agência sobre os elementos na tela, o que aproxima a "montagem proibida” de André Bazin deste novo objeto dos jogos digitais. Desta maneira, representar ações e reações no mesmo quadro é essencial para manter o envolvimento. O ônus é enfraquecer a força das elipses como recursos da narrativa e ter de transformar saltos no tempo em percursos no espaço, um padrão para jogos digitais.

\section{BIBLIOGRAFIA}

Abel, Richard. 2005. Encyclopedia of early cinema. Abingdon, Oxon, OX: Routledge.

Bazin, André. 1991. O Cinema - Ensaios. São Paulo, SP: Brasiliense.

Bianconi, Lorenzo, and Giorgio Pestelli. 2002. Opera on stage. Chicago: University of Chicago Press. 
Bogost, Ian. 2007. Persuasive Games: The Expressive Power of Videogames. Cambridge: MIT Press.

Bolter, Jay David, and Richard Grusin. 2000. Remediation: Understanding New Media. Cambridge: MIT Press.

Crawford, Chris. 1982. The Art of Computer Game Design. Berkeley: Osborne/McGraw-Hill.

Darley, Andrew. 2000. Visual digital culture: surface play and spectacle in new media genres. London: Routledge.

Helfand, Jessica. 2001. Screen: Essays on Graphic Design, New Media and Visual Culture. New York, NY: Princeton Architectural Press.

Huhtamo, Erkki. 2013. Illusions in Motion. Cambridge: MIT Press.

Huizinga, Johan. 2012. Homo Ludens. Tradução de J. P. Monteiro. São Paulo: Perspectiva, $7^{a}$ edição.

Jacobs, Steven. 2011. Framing pictures: film and the visual arts. Edinburgh: Edinburgh University Press.

Jost, François, and André Gaudreault. 2010. Narrativa Cinematográfica. Brasília, DF: Ed. Unb.

Kent, Steve L. 2001. The ultimate history of video games: from Pong to Pokémon and beyond: the story behind the craze that touched our lives and changed the world. Roseville, CA: Prima Pub..

Koster, Raph.2005. A theory of fun for game design. Scottsdale, AZ: Paraglyph Press.

Kuhn, Thomas. 2013. "As revoluções como mudanças de concepção de mundo". In A Nuvem: Uma antologia para professores, mediadores e aficionados da $9^{a}$ Bienal do Mercosul, ed. Sofía Hernández Chong Cuy, Mônica Hoff, 75-110. Porto Alegre, RS: Fundação Bienal de Artes Visuais do Mercosul.

Montfort, Nick, and Ian Bogost. 2009. Racing the beam: the Atari Video computer system. Cambridge, MA: MIT Press.

Miller, Ron. 2006. Special Effects - An Introduction to Movie Magic. Minneapolis, MN: Twenty-First Century Books.

Napoli, Philip M. 2010. Audience Evolution - New Technologies and The Transformation of Media Audiences. New York, NY: Columbia University Press.

Palmer, Shelly. 2006. Television Disrupted: The Transition From Network To Networked TV. Nova York, NY: Focal Press.

Peucker, Brigitte. 2007. The Material Image: Art and the Real in Film. Stanford: Stanford University Press.

Pinel, Vincent. 2001. Le Montage: l'espace et le temps du film. Paris: Cahiers du cinéma / Scérén [CNDP-CRDP]. 
Poole, Steven. 2000. Trigger Happy. Nova York: Arcade Publishing.

Ruffles, Tom. 2004. Ghost images: cinema of the afterlife. Jefferson, NC: McFarland \& Co.

Salen, Katie and Zimmerman, Eric. 2003. Rules of Play: Game Design Fundamentals. Cambridge: MIT Press.

Siety, Emmanuel. 2001. Le Plan au commecement du cinéma. Paris: Cahiers du cinéma / Scérén [CNDP-CRDP].

Spector, Warren. 2004. "What is gameplay?" In Difficult Questions about Video Games, ed. James Newmann, Iain Simons, 77. Londres: Suppose Partners.

Wolf, Mark. 2001. The Medium of the Video Game. Austin: University of Texas Press. Kindle Edition.

\section{REFERÊNCIAS A JOGOS}

Adventures of Tron [game, Atari 2600] APh Technological Consulting. EUA, 1982.

Altered Beast [game, arcade] Sega. Japão, 1987

Another World [game, Amiga] Delphine Software. França, 1991.

Assassin's Creed IV: Black Flag [game, PlayStation 4] Ubisoft Montreal. Canadá, 2013.

Batman Arkham Knight [game, PlayStation 4] Rocksteady. Inglaterra, 1991.

Berzerk [game, Atari 2600] Stern. EUA, 1982.

Bomb Jack [game, arcade] Tehkan. Japão, 1984.

Donkey Kong [game, arcade] Nintendo. Japão, 1981.

Double Dragon [game, arcade] Technōs Japan. Japão, 1987

Endless Ocean [game, Nintendo Wii] Arika. Japão, 2007.

Flight Simulator 2.0 [game, MS-DOS] Microsoft. EUA, 1984.

Galaga [game, arcade] Namco. Japão, 1981.

Galaxian [game, arcade] Namco. Japão, 1979.

Grand Theft Auto [game, Windows] Rockstar North Ltd.. Escócia, 1997.

Her Story [game, iOS] Sam Barlow. Inglaterra, 2015.

Jungle Hunt [game, Atari 2600] Taito. Japão, 1982.

Karate Champ [game, arcade] Technōs Japan. Japão, 1984.

Myst [game, Macintosh] Cyan, Inc.. EUA, 1993. 
Pac-Man [game, arcade] Namco. Japão, 1980.

Prince of Persia: The Sands of Time [game, PlayStation 2] Ubisoft Montreal. Canadá, 2003.

Quantum Break [game, Xbox One] Remedy Entertainment, Finlândia, 2016.

Raiders of the Lost Ark [game, Atari 2600] Atari. EUA, 1982.

Samurai Shodown [game, arcade] SNK. Japão, 1993.

Space Invaders [game, arcade] Taito. Japão, 1978.

Star Wars: The Empire Strikes Back [game, Atari 2600] Parker Brothers. EUA, 1982.

Street Fighter II: The World Warrior [game, arcade] Capcom. Japão, 1991.

Super Mario 64 [game, Nintendo 64] Nintendo. Japão, 1996.

Super Mario Bros. 1 [game, NES] Nintendo. Japão, 1985.

Super Mario Galaxy [game, Nintendo Wii] Nintendo. Japão, 2007.

Super Mario Galaxy 2 [game, Nintendo Wii] Nintendo. Japão, 2009.

Super Monkey Ball [game, Nintendo Gamecube] Amusement Vision. Japão, 2001.

Teenage Mutant Ninja Turtles [game, arcade] Konami. Japão, 1989.

Tomb Raider [game, PlayStation 1] Eidos Interactive, Reino Unido, 1996.

The Legend of Zelda: The Wind Waker [game, Nintendo Gamecube] Nintendo. Japão, 2002.

The Legend of Zelda: Breath of the Wild [game, Nintendo Switch] Nintendo. Japão, 2017.

The Lord of the Rings: The Return of the King [game, PlayStation 2] EA Redwood Shores. EUA, 2003.

Uncharted 2: Among Thieves [game, PlayStation 3] Naughty Dog. EUA, 2009.

Uncharted 4: A Thief's End [game, PlayStation 4] Naughty Dog. EUA, 2016.

Yie Ar Kung Fu [game, MSX] Konami. Japão, 1985.

Zork. [game, TRS-80] Personal Software. EUA, 1980.

\section{FILMOGRAFIA}


Lara Croft: Tomb Raider [filme] Dir. Simon West. Mutual Film Company et al., Estados Unidos et al., 2001. 100mins.

O Balão Vermelho [filme] Dir. Albert Lamorisse. Films Montsouris, França, 1956. 35mins.

O Cavaleiro das Trevas Renasce [filme] Dir. Christopher Nolan. Legendary Pictures et al., Inglaterra, 2012. 165mins.

Street Fighter - A Batalha Final [filme] Dir. St even E. de Souza. Capcom, Estados Unidos et al., 1994. 102mins.

Warcraft [filme] Dir. Duncan Jones. Legendary Pictures et al., Estados Unidos, 2016. 123mins.

Wing Commander - Comando Espacial [filme] Dir. Chris Roberts. Mutual Film Company et al., Estados Unidos et al., 1999. 100mins. 